\title{
CONDENSED COMBUSTION PRODUCTS FROM BURNING OF NANOALUMINUM-BASED PROPELLANTS: PROPERTIES AND FORMATION MECHANISM
}

\section{Babuk, A. Glebov, I. Dolotkazin, A. Conti, L. Galfetti, L. T. DeLuca, and A. Vorozhtsov}

\begin{abstract}
The experimental results obtained within a joint international research effort regarding the formation of condensed combustion products from nanoaluminum-based solid propellants (SPs) are reported. Data on the size, structure, chemical composition, and quantity of condensed combustion products (CCPs) as well as conditions of their formation are discussed. On the basis of the collected experimental data, a general physical picture of condensed combustion products formation is portrayed. The results of this study allow carrying out the analysis of good quality propellants using nanoaluminum.
\end{abstract}

\section{INTRODUCTION}

One of the modern directions to improve SPs is to resort to nanosized components. Within the framework of this direction, there is a realistic opportunity for essential changes of the burning rate law, besides the potential power increase that SP can fulfill. During last decade, researchers of various countries undertook vigorous efforts on experimental studies regarding burning processes of nanoaluminum-based propellants. As a rule, aluminum powders with particle size of $\sim 100 \mathrm{~nm}$ were used.

It can be stated that the burning rate of SPs grows essentially at transition from traditional powders of aluminum to nanoaluminum [1-9]. However, the data on influence on the burning rate magnitude and its dependence on pressure remain inconsistent [1-9].

There exist two aspects of the influence of nanoaluminum on powder propellant characteristics. First, using this component yields CCPs capable of promoting a decrease in specific impulse losses. Second, using metal fuel in the form of nanostructure, i.e., particles without a volumetric phase, results in increasing the propellant energy potential due to utilizing not only chemical energy but also the

This is an Open Access article distributed under the terms of the Creative Commons Attribution-Noncommercial License 3.0, which permits unrestricted use, distribution, and reproduction in any noncommercial medium, provvided the original work is properly cited. 
energy of intermolecular interaction [10]. It is worth emphasizing that creation of propellants based on nanostructures is at the most initial stage nowadays. In general, such problems as creation of nanostructures and their introduction to propellant composition have not yet been solved. There is only a limited number of publications (see, for example, [11]) where such propellants are considered.

Thus, the influence of nanoaluminum on the propellant energetic properties is connected with the influence of this component on the CCP characteristics. The basic process determining these characteristics is the agglomeration process.

There exist different interpretations for describing the influence of nanoaluminum on metal fuel agglomeration at the surface layer of the burning propellant.

Virtually, in all works $([4,12]$, etc.) carried out so far, introduction of metal fuel in composition of nanoparticles implied a reduction of the CCP particle size. However, the statement that nanoaluminum is the universal "tool" eliminating the agglomeration process is considered inexact. In view of it, it is necessary to take into account two circumstances.

First, the size of initial nanoaluminum particles is one-two orders of magnitude less than the particle size of conventional powders thus producing particle agglomerates of a rather small size.

Second, under certain conditions, agglomeration mechanism does not depend on the individual properties of initial particles. For example, for class A propellants [13], agglomerates are formed from a "liquid $\mathrm{Al}-\mathrm{Al}_{2} \mathrm{O}_{3}$ " at the surface layer of burning propellant when the ignition temperature of metal is less than the decomposition temperature of carbonaceous elements. (Reduction of particles size results in the reduction of metal ignition temperature.)

Besides, there is no information about the characteristics of all CCPs formed in the course of burning of nanoaluminum-based propellants.

As a result, there is no commonly accepted understanding of the mechanism of CCPs formation at burning of nanoaluminum-based propellants. As this mechanism is directly connected with the influence of metal fuel (MF) on the propellant burning rate, there are also problems with the description of the burning mechanism of propellants of the considered class as a whole.

The circumstances discussed above stimulated the present work which had the following objectives:

- to obtain experimental information on the entire set of CCPs for burning nanoaluminum-based propellants depending on the oxidizer type and burning conditions;

- to formulate basic principles of the CCPs formation mechanism for nanoaluminum-based propellants; and

- to provide recommendations on the optimum way of using nanoaluminum in propellant composition. 


\section{EXPERIMENTAL TECHNIQUES}

The implemented experimental techniques include:

- quench-collection of CCPs in the gas-phase zone above the burning surface and direct study of the products including mass, chemical, and structural analyses, as well as particle size measurements;

- measurement of steady-state propellant burning rate;

- study of combustion residues obtained using special plates; and

- high-speed and high-resolution digital visualization of burning processes.

The essential features of the implemented techniques are the opportunities to collect no less than $95 \%$ by weight of all CCPs and to analyze particles from tens nanometers up to thousand micrometers size. The description of the techniques was given previously in a number of authors' publications [14-18].

For the quantitative description of the processes involved, the following characteristics are used:

$f_{m}(D)$ - the mass function of size distribution density for agglomerates;

$f_{m}(d)$ - the mass function of size distribution density for smoke oxide particles;

$Z_{m}$ — the fraction of unburned metal in agglomerates relative to initial metal in propellant;

$Z_{m}^{\text {ox }}$ — the fraction of initial metal in propellant contributing to oxide formation in agglomerates;

$Z_{m}^{a}$ — the fraction of initial metal in propellant contributing to the formation of agglomerates;

$\eta$ — the mass fraction of oxide in agglomerate;

$D_{43}$ - the mass-mean diameter of agglomerates, $\mu \mathrm{m}$;

$d_{43}$ — the mass-mean diameter of smoke oxide particles, nm;

$r_{b}$ — the steady-state propellant burning rate, $\mathrm{mm} / \mathrm{s}$.

Qualitative information was obtained by analyzing the photographs of particles collected, their microsections, combustion residues on the plates, as well as video films of burning.

The experiments were performed for compositions based on inert binder and various oxidizers: ammonium perchlorate (AP), cyclotrimethylene tetranitramine (HMX), and ammonium nitrate (AN). Tables 1 and 2 show the characteristics of some of the investigated compositions. 
Table 1 AN-based composition

\begin{tabular}{|c|c|c|}
\hline Substance, \% & AN1 & AN2 \\
\hline $\mathrm{AN}_{\text {coarse }}^{a}$ & 33 & 33 \\
\hline AN fine ${ }^{b}$ & 33 & 33 \\
\hline $\mathrm{Al}$ regular $^{c}$ & 22 & - \\
\hline $\mathrm{Al}$ nanosized $^{d}$ & - & 22 \\
\hline Isoprene rubber & 2.4 & 2.4 \\
\hline Oil $\left(\mathrm{C}_{19} \mathrm{H}_{35}\right)$ & 9 & 9 \\
\hline Additives & 0.6 & 0.6 \\
\hline \multicolumn{3}{|c|}{$\begin{array}{l}{ }^{a} \text { Size of particles } 250-350 \mu \mathrm{m} . \\
{ }^{b} \text { Size of particles } 40-70 \mu \mathrm{m} . \\
{ }^{c} \text { Mass-mean diameter of particles } \\
10.5 \mu \mathrm{m} .\end{array}$} \\
\hline $\begin{array}{l}{ }^{d} \text { Specific } \text { surface } \\
\sim 0.1 \mu \mathrm{m}) .\end{array}$ & $10-2$ & ${ }^{2} / g \quad$ (size \\
\hline
\end{tabular}

Table 2 (AP-HMX)-based composition

\begin{tabular}{lcrcc}
\hline Substance, \% & $\mathrm{N} 1$ & $\mathrm{~N} 2$ & $\mathrm{~N} 3$ & $\mathrm{~N} 4$ \\
\hline Plasticized binder & 14.0 & 14.0 & 14.0 & 14.0 \\
$\mathrm{AP}^{a}$ & 76.9 & 68.9 & 65.9 & 49.9 \\
Al nano-sized $^{b}$ & 9.0 & 9.0 & 20.0 & 16.0 \\
Al regular & - & 8.0 & - & - \\
HMX & - & - & - & 20.0 \\
\hline
\end{tabular}

${ }^{a}$ Size of particles $160-315 \mu \mathrm{m}$.

${ }^{b}$ Specific surface $12.4 \mathrm{~m}^{2} / \mathrm{g}$.

\section{RESULTS}

\subsection{Condensed Combustion Products}

In general, the CCP particles have a rather wide range of sizes (from fractions of micrometer up to thousand micrometers). However, irrespective of the particle size, it is always possible to allocate two fractions, which are formed by particles of two types: agglomerates and smoke oxide particles (SOPs). Agglomerates are the particles formed due to merging of condensed substances at the propellant surface layer. Smoke oxide particles are the products of metal combustion in this layer and in the layer above the propellant surface in the gas phase.

The grounds for the allocation of these fractions are provided by the mass function of size distribution density of particles. The specified fractions correspond to separate modes (set of modes). It is supposed that the size of agglomerates cannot be smaller than the size of initial metal particles.

Let us consider the influence of nanoaluminum on the properties of particles within the specified fractions for the propellants of different compositions.

\subsubsection{Agglomerates}

\section{A. AN-based propellants}

The results of studies of AN-based propellants were published in [19, 20]. The most remarkable consequences of using nanoaluminum are as follows.

Application of nanoaluminum results primarily in the formation of "hollow" agglomerates. They consist of the oxide shell with a comparatively small metal 
particle embedded. Besides, the important consequence of using nanoaluminum is a considerable reduction of the agglomerate size: the size decreases by a factor of 5-6. The presence of nanoaluminum also reduces the mass of agglomerates (parameter $Z_{m}^{a}$ ) and increases the mass of oxide in agglomerates (growth of parameters $Z_{m}^{\mathrm{ox}}$ and $\eta$ ).

\section{B. (AP-HMX)-based propellants}

With these propellants, the agglomerates of three known types are observed, namely, "matrix," "oxide cap," and "hollow" agglomerates [20]. The overwhelming majority of the collected agglomerates exceeding 20-micron size are attributed to the second type, i.e., to the agglomerates with "oxide cap." Among the agglomerates of fine fraction, the new type of agglomerates was detected. The agglomerate of this type is a particle of metal covered with oxide. Despite known problems of studying the structure of small-size particles, it is apparently possible to claim that such agglomerates do exist. The structure of the agglomerates formed in the course of burning of the investigated compositions is shown schematically in Fig. 1.

For the investigated compositions, two types of particle agglomeration can take place. They differ by the agglomeration process and agglomerate type.

In the first, the formation of agglomerates with a size close to that observed at burning of propellants with microsized aluminum is possible. In this case, the mass function of size distribution density of agglomerates is unimodal and varies insignificantly with pressure (Fig. 2).

In the second, the formation of agglomerates of essentially smaller size (Fig. 3) is possible. In this case, there is no essential influence of burning conditions on the agglomerate size distribution.

The amount and chemical composition of agglomerates in the abovementioned types of agglomeration are different. In the first, the values of pa-

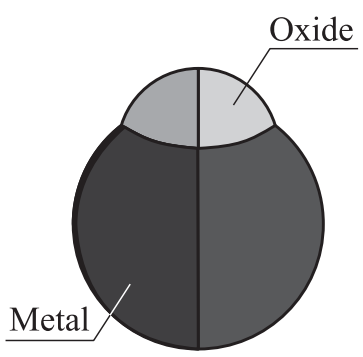

(a)

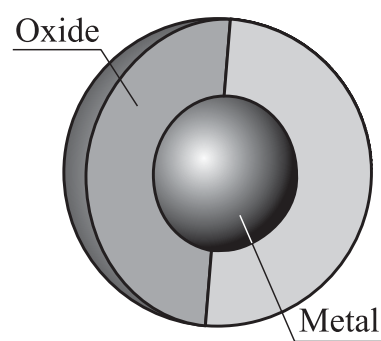

(b)

Figure 1 The structure of agglomerates: (a) "oxide cap" and (b) metal covered with oxide 


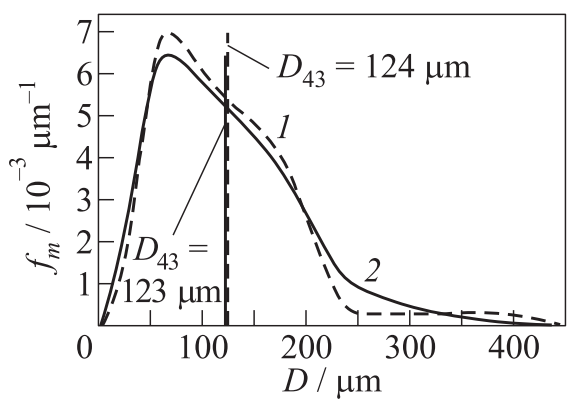

Figure 2 The mass function of size distribution density of agglomerates for composition $\mathrm{N} 2: 1-\mathrm{MPa}$ and $2-6 \mathrm{MPa}$

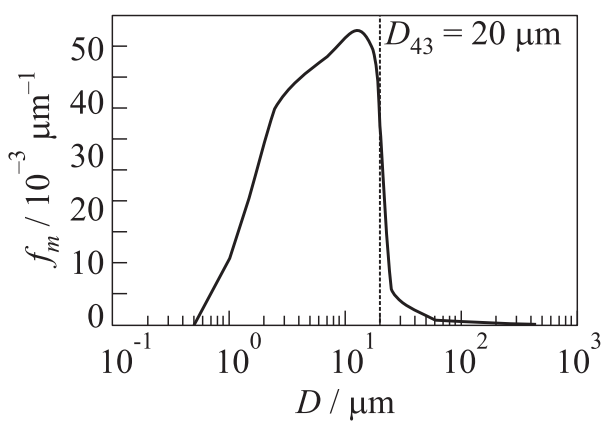

Figure 3 The mass function of size distribution density of agglomerates for composition $\mathrm{N} 4(P=6.0 \mathrm{MPa})$

rameter $Z_{m}^{a}$ are rather "moderate" $\left(Z_{m}^{a} \sim 0.5\right)$, whereas in the second, these values are large $\left(Z_{m}^{a} \sim 0.9\right)$. Besides, a higher content of oxide in agglomerates is typical of the second type of agglomeration.

\subsubsection{Smoke oxide particles}

Smoke oxide particles have the regular spherical shape (Fig. 4). As a rule, these are the particles of white color. At present, there are no data on the internal
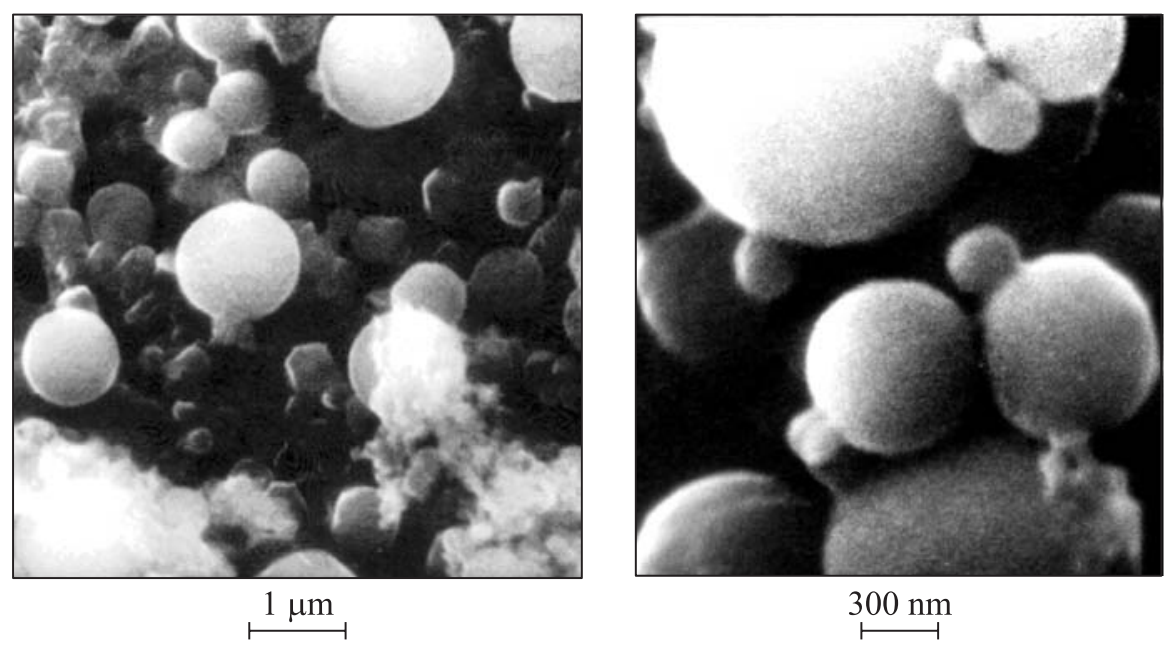

Figure 4 Electron microscope images of SOPs 


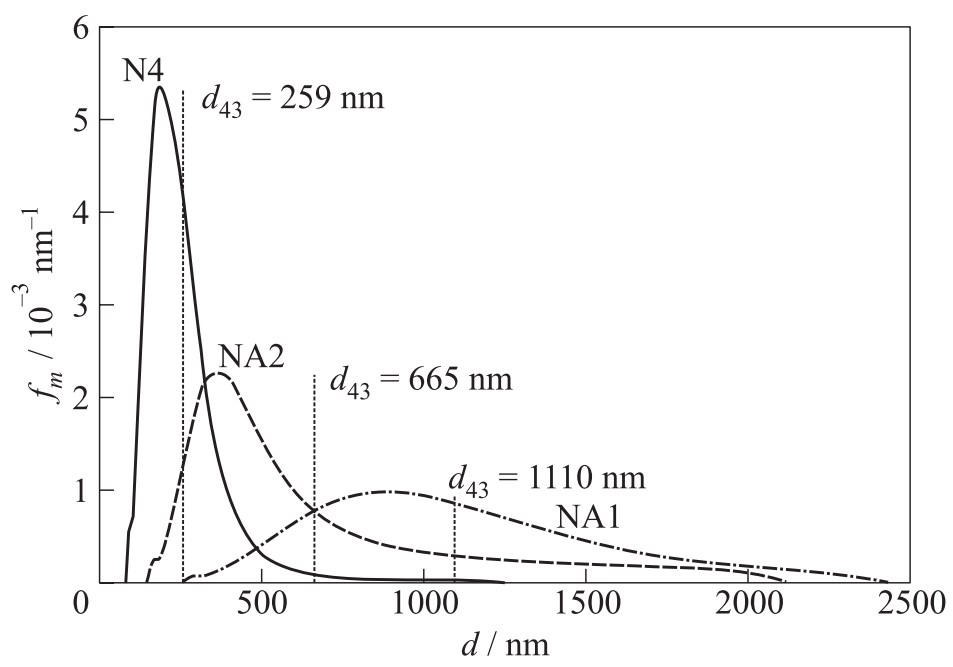

Figure 5 The mass function of SOPs size distribution density for some compositions

structure of such particles. However, there are grounds to assume that some particles have gas cavities.

\section{A. AN-based propellants}

The most distinctive features of SOPs are their rather small mass fraction in the composition of CCPs $\left(1-Z_{m}^{a}\right)[19]$ and their unusually large size (Fig. 5). Worth emphasizing is the obvious unterrelation between the sizes of agglomerates and SOPs: with increasing the size of agglomerates, the size of SOPs also increases. The use of nanoaluminum, which results in decreasing the agglomerate size, results in decreasing the SOPs size. The mass function of SOPs size distribution density has only one mode.

B. (AP-HMX)-based propellants

The most distinctive feature of all compositions based on nanosized aluminum is unusually small size of SOPs (see Fig. 5). The SOPs mass fraction in composition of CCPs is determined by parameter $Z_{m}^{a}$ and depends on the agglomeration process.

\subsection{Characteristics of Surface Layer}

The surface layer structure was studied by analyzing the combustion residue on inert plates. It was presumed that those residues corresponded to the specific structure of the surface layer, which plays a very important role in the 


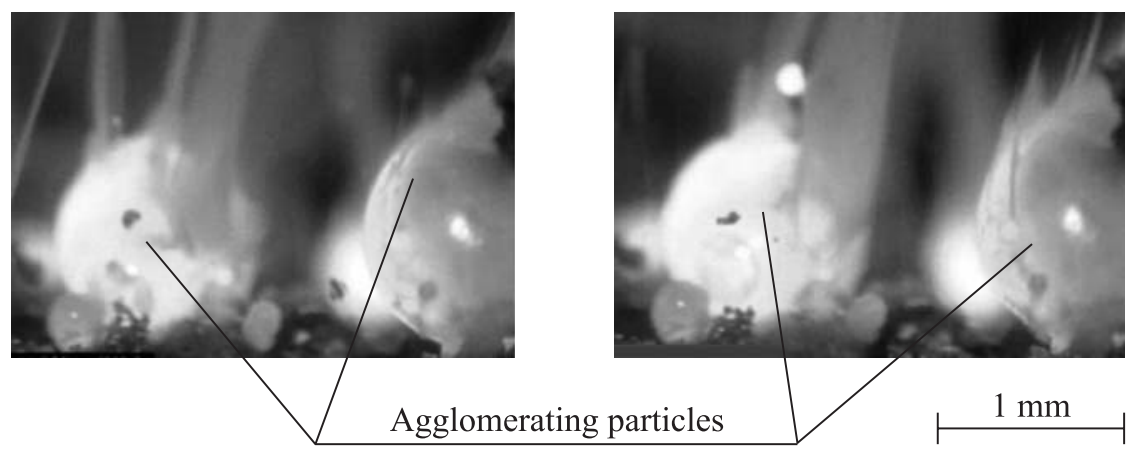

Figure 6 Two subsequent images of the surface layer of AN-based composition $(P=3.0 \mathrm{MPa}, \Delta t=1 \mathrm{~ms})$

process of propellant combustion and was given the name of the skeleton layer (SL) [13].

For AN-based propellants, the SL has the characteristic properties of class A propellants [13]. The SL basis is made of a carbon skeleton and the pores of the carbon skeleton are appreciably filled with "liquid $\mathrm{Al}-\mathrm{Al}_{2} \mathrm{O}_{3}$." The $\mathrm{SL}$ of these propellants features a high degree of continuity, covering virtually the entire burning surface of propellant and keeping it free from oxidizer particles. The carbon skeleton thickness is $\sim 400-500 \mu \mathrm{m}$. Using nanoaluminum does not result in a significant effect as far as SL properties are concerned.

The situation is different for propellants based on AP and HMX. For the first type of agglomeration, SL structure is similar to that observed for class A propellants. However, the SL possesses a smaller degree of continuity as against ANbased propellants, covering only a part of the surface of a composition binder metal fuel. For the second type of agglomeration, SL has a metal skeleton, which is a certain analogue of an SL of class $\mathbf{B}$ propellants [13]. However, optical microscope studies do not allow detecting separate particles forming this skeleton. One can assume that a similar skeleton of nanosized particles is formed during propellant manufacturing when aluminum particles coagulate with each other after being introduced into the propellant mixture, and form "metal strings." The metal skeleton is thus formed in the propellant bulk after hardening. Apparently, this metal skeleton can determine the basic properties of CCPs formed during burning.

Results of visualization of burning area confirm in general the above mentioned data on properties of a surface layer. Figure 6 shows the image of a surface layer for the AN-based composition. 


\section{PHYSICAL CONCEPT OF CONDENSED COMBUSTION PRODUCT FORMATION}

The formation of CCPs depends on both the opportunity of SL formation and its properties. It can be asserted that agglomerates form only from the metal fuel participating in SL formation.

The necessary condition of SL formation is the availability of connected structures from metal particles $[13,21]$. In turn, their occurrence can be closely connected with two phenomena:

(1) formation of carbon skeleton during propellant burning; and

(2) creation of the connected structures from the initial metal particles in the propellant.

The former depends on the propellant composition, i.e., binder and oxidizer, and the latter depends on the manufacturing procedure.

\section{A. AN-based propellants}

The results of previous works $[19,20]$ show that, owing to the formation of a continuous AN melted layer on the surface of the burning propellant, the heterogeneity of propellant structure is leveled; also, the formation of carbon skeleton and, hence, SL occurs through all structural formations. This ensures a high degree of participation of MF in agglomeration.

The burning law corresponds to class A propellants, i.e., the temperature of metal fuel ignition $\left(T_{\operatorname{ig} m}\right)$ is lower than the decomposition temperature of carbonaceous elements $\left(T_{\mathrm{dc}}\right)[13]$. It is obvious that for this class of propellants, the initial metal particles lose their individuality during agglomeration and the "initial material" for agglomerates is "liquid $\mathrm{Al}-\mathrm{Al}_{2} \mathrm{O}_{3}$."

There are grounds to believe that the use of nanoaluminum results in reducing the $T_{\text {ig } m}$ value. Consequently, one obtains earlier MF ignition, the growth of the heat flux coming back to the propellant condensed phase, and, hence, the growth of the propellant burning rate. Finally, the agglomerating particle on the SL top surface and actual agglomerates decrease in size.

Small sizes of these particles and significant life times of SL surfaces result in the effective evolutionary process of particle agglomeration on this surface. This process is understood as a sequence of physical and chemical transformations, which the specified particles undergo. This process leads to a significant amount of agglomerated metal and to the formation of "hollow" agglomerates.

One of the outcomes of this process is the burning of metal agglomerates in the gas phase with the formation of SOPs. Thus, this process is a source of SOPs at burning of the propellants of the considered type. The size of formed 
oxide particles depends on the time of their stay in the "trail" of burning particles where condensation and coagulation phenomena take place [18]. This size increases with the time of stay and vice versa: reduction of the size of the agglomerating particles results in the reduction of this time. As a consequence, there is an essential reduction of SOPs size when using nanoaluminum. The uniformity of SOPs formation results in a mass function of SOPs size distribution density with only one mode.

\section{B. (AP-HMX)-based propellants}

For these propellants (remind that the propellants based on inert binders are considered), the heterogeneity of their structure significantly influences the SL formation [13]. Pertinently, for such structural formations, one can use the concepts of "pocket" and "interpocket bridge." The formation of carbon skeleton does not occur within the "interpocket bridges," and, hence, SL. Thus, the mass fraction of "pockets" in a propellant can be used for an estimation of a share of the MF participating in agglomeration. A similar situation obviously takes place in those cases when initial particles keep their individuality and do not form a vast interconnected structure.

Experimental data provide the grounds to believe that for the first type of particle agglomeration, initial nanoaluminum grains keep their individuality in the propellant and SL formation is determined by the propellant structure. In this case, SL properties correspond to those relevant to class A propellants, i.e., $T_{\text {ig } m}<T_{\text {dc }}$.

The use of the structure model $[8,22]$, providing the estimation of a share of "pockets" in the propellant and the function of "pockets" size distribution, has allowed drawing a conclusion on affinity of "pockets" mass fraction in a composition of binder - MF $\left(g_{p}\right)$ to parameter $Z_{m}^{a}$ and on the realization of the "pocket" mechanism of agglomeration. In this case, particles of both AP and HMX participate in the formation of "pockets." (For example, for composition $\mathrm{N} 2$, the parameter $g_{p}$ is equal to 0.45 , and mass-mean diameter of agglomerates formed due to the "pocket" mechanism is equal to $137 \mu \mathrm{m}$.)

The formation of SOPs for the considered propellants proceeds in conformity with two mechanisms: at combustion of nonagglomerating MF in a layer above the surface and burning of agglomerating particles on the SL surface. However, in this case, the evolution of agglomerating particles on the surface of SL is not important, and the second mechanism can be apparently neglected. The basic mode of burning of nonagglomerating $\mathrm{MF}$ is a heterogeneous mode $[8,13]$. Consequently, there is the affinity of SOPs size to the initial nanoaluminum size. In general, one cannot exclude possible presence of SOPs in gas pores.

For the second type of agglomeration, connected structures can apparently form from the initial MF particles in the propellant bulk. It is necessary to emphasize that the occurrence of such situation is promoted by very small size 
of MF particles, which results in a large probability of contact between particles during propellant manufacturing.

In this case, the occurrence of an SL is not connected with the burning process. Also, the structure of propellant does not influence the SL formation and the share of the initial MF participating in its formation. Hence, the agglomeration depends on the degree of coherence of initial particles in the propellant. Experimental data provide the grounds to believe that the latter is rather great. Specific features of SL structure result in the growth of thermal losses with metal particles during burning and, therefore, in the growth of their ignition temperature. Under these circumstances, the condition $T_{\mathrm{ig} m}>T_{\mathrm{dc}}$ is likely to take place. Thus, the SL properties are similar to those relevant to class $\mathbf{B}$ propellants [13], i.e., the SL is the metal skeleton consisting of initial metal particles fastened to each other. After ignition of SL particles, they start merging and form agglomerates. The size and structure of the agglomerates depend on the time of particles stay at the SL surfaces and on the specific features of agglomerating particles evolution. The time of stay is determined basically by the SL nonuniformity [23]. In the case considered, the occurrence of nonuniformities responsible for the outflow of agglomerating particles from the SL is connected with the propellant manufacturing process and does not depend on the actual burning process. This, apparently, determines a weak dependence of the agglomerate size on pressure.

After ignition, the burning of particles proceeds in heterogeneous mode [8]. Burning in this mode can be considered as one of the stages of the evolutionary process of agglomerating particles on the SL surface. Small sizes of agglomerating particles and high level of thermal losses result in a prolonged duration of this stage. As a consequence, some particles do not burn in the gas-phase mode, and agglomerates of a new type are formed.

Smoke oxide particles form as a result of combustion of a small part of initial metal, which does not form connected structures. The mechanism of formation of these particles does not apparently differ from that considered earlier for the first type of agglomeration.

The propellants exhibiting burning with the first and second types of agglomeration will be referred to as propellants Nano1 and Nano2, respectively.

When comparing the propellants of these types, the preference is unclear. In the case of Nano2 propellants, the problem of slag formation in the motor chamber virtually does not exist. However, the possibility of formation of metal agglomerates covered with oxide can result in increasing of specific impulse $\left(J_{\mathrm{sp}}\right)$ losses. In the case of Nano1 propellants, a situation with the optimum ratio between two basic CCPs fractions is potentially possible, which provides minimum slag formation and minimum $J_{\text {sp }}$ losses. Besides, for the propellants of this type, typically higher influence of MF on the propellant burning rate is observed which results in reducing the pressure exponent [8]. The above-mentioned ideas are illustrated schematically in Fig. 7. 


\begin{tabular}{|l|l|l|}
\hline Nano1 propellant type & \multicolumn{2}{|c|}{ Opportunity of problem solution } \\
\hline
\end{tabular}

Figure 7 Type and quality of propellants based on nanosized aluminum

\section{CONCLUDING REMARKS}

The results of the study reported herein allow establishing the specific features of CCPs formation during the combustion of propellants based on nanosized aluminum. These results can be used both for manufacturing similar propellants and for improving the general theory of aluminized propellant burning.

\section{ACKNOWLEDGMENTS}

This work was supported financially by the International Science and Technology Center (ISTC), Moscow.

\section{REFERENCES}

1. Mench, M. M., C.L. Yeh, and K.K. Kuo. 1998. Propellant burning rate enhancement and thermal behaviour of ultra-fine aluminum powders (ALEX). 29th Annual Conference (International) of ICT Proceedings. Paper 30.

2. Arkhipov, V. A., G. V. Ivanov, A. G. Korotkikh, V. V. Medvedev, and V. G. Surkov. 2000. Features of ignition and burning of composite propellants with ultra-fine aluminum (ALEX). International Seminar on Intra-Chamber Processes, Combustion 
and Gas Dynamics of Dispersed Systems Proceedings. St. Petersburg. 80-81. (In Russian.)

3. Lessard, P., F. Beaupre, and P. Brousseau. 2001. Burn rate studies of composite propellants containing ultra-fine metals. 32nd Annual Conference (International) of ICT Proceedings. Paper 88.

4. Dokhan, A., E. W. Price, R. K. Sigman, and J. M. Seitzman. 2001. The effects of Al particle size on the burning rate and residual oxide in aluminized propellants. $37 \mathrm{th}$ AIAA/ASME/ASEE Joint Propulsion Conference and Exhibit. Salt Lake City, UT. AIAA Paper No.01-3581.

5. Arkhipov, V.A., A. G. Korotkikh, and V.T. Kuznezov. 2002. Ignition and combustion of condensed systems containing ultra-fine aluminum. Fundamental and applied problems of modern mechanics. Tomsk. 28-29. (In Russian.)

6. Baschung, B., D. Grune, H. H. Licht, and M. Samirant. 2002. Combustion phenomena of a solid propellant based on aluminum powder. In: Combustion of energetic materials. Eds. K. Kuo and L. T. DeLuca. N.Y. 219-23.

7. Armstrong, R. W., M. P. Kramer, and W. H. Wilson. 2003. The power and strength of energetic/reactive nano-materials. 9th Workshop (International) on Combustion Proceedings. Lerici, La Spezia, Italy. Bergamo, Italy: Grafiche GSS. 56-57.

8. Babuk, V.A., V.A. Vasilyev, I. N. Dolotkazin, and V. V. Sviridov. 2003. Metal fuel as component of high-performance solid rocket propellants: Problems and applications perspective. In: Rocket propulsion: Present and future. Ed. L. T. DeLuca. Bergamo, Italy: Grafiche GSS. Paper 26.

9. Vorozhsov, A.B., V. Arkhipov, S. Bondarchuk, A. Korotkikh, V. Kuznezov, V. Surkov, and V. Sedoi. 2003. Ignition and combustion of solid and gelled propellants containing ultra-fine aluminum. In: Rocket propulsion: Present and future. Ed. L. T. DeLuca. Bergamo, Italy: Grafiche GSS. Paper 36.

10. Babuk, V.A. 2004. Nanostructures, as new object of study of the nature world. Properties, condition of application and obtaining,. Workshop (International) on MEMS and Nanotechnology Integration (MNI): Applications Proceedings. Montreux, Switzerland. 82.

11. Ramaswamy, A.L., P. Kaste, and S. Trevino. 2003. Nano-scale ingredients for environmentally benign propellants. In: Rocket propulsion: Present and future. Ed. L. T. DeLuca. Bergamo, Italy: Grafiche GSS. Paper 35.

12. Glotov, O. G., V.E. Zarko, and M.W. Beckstead. Agglomerated and oxide particle generated in combustion of ALEX containing solid propellants. 31st Annual Conference (International) of ICT Proceedings. Paper 130.

13. Babuk, V.A., V.A. Vasilyev, and V.V. Sviridov. 2000. Formation of condensed combustion products at the burning surface of solid rocket propellant. In: Solid propellant chemistry, combustion, and motor interior ballistics. Eds. V. Yang, T. B. Brill, and W.Z. Ren. Progress in astronautics and aeronautics ser. Reston, VA: American Institute of Aeronautics and Astronautics. Vol. 185. Ch. 2.21:749-76.

14. Babuk, V.A., V.A. Vasilyev, and M.S. Malakhov. 1999. Condensed combustion products at the burning surface of aluminized solid propellant. J. Propul. Power 15(6):783-94. 
15. DeLuca, L. T., L. Galfetti, F. Severini, M. Galeotta, R. DeAmicis, V. A. Babuk, B. N. Kondrikov, and A.B. Vorozhtsov. 2003. Solid rocket motors for cheap access to space. Conference "Novel Energetic Materials and Application." Lerici, La Spezia. Bergamo, Italy: Grafiche GSS.

16. Taiariol, P., M. Galeotta, and L. T. DeLuca. 2003. Burning waves visualization with digital high speed color camera. Conference "Novel Energetic Materials and Application." Lerici, La Spezia. Bergamo, Italy: Grafiche GSS.

17. Galfetti, L., F. Severini, L. T. DeLuca, G. Marra, and R. Braglia. 2004. Ballistics and condensed combustion residues of aluminized solid rocket propellants. In: Novel energetic materials and applications. Eds. L. T. DeLuca, L. Galfetti, and R. A. Pesce-Rodriguez. Bergamo, Italy: Grafiche GSS. Paper 18.

18. Babuk, V.A. 2007. Problems in studying formation of smoke oxide particles in combustion of aluminized solid propellants. Combust. Explosion Shock Waves 43(1):3845.

19. Babuk, V.A., V.A. Vasilyev, A.A. Glebov, I. N. Dolotkazin, M. Galeotta, and L. T. DeLuca. 2004. Combustion mechanisms of AN-based aluminized solid rocket propellants. In: Novel energetic materials and applications. Eds. L. T. DeLuca, L. Galfetti, and R. A. Pesce-Rodriguez. Bergamo, Italy: Grafiche GSS 2004. Paper 44.

20. Babuk, V.A., A. Glebov, V. A. Arkhipov, A. B. Vorozhtsov, G. F. Klyakin, F. Severini, L. Galfetti, and L. T. DeLuca. 2005. Dual-oxidizer solid rocket propellants for low-cost access to space. In: In-space propulsion. Eds. L. T. DeLuca, R. L. Sackheim, and B. A. Palaszewski. Italy: Grafiche GSS. Paper 15.

21. Babuk, V.A., I. N. Dolotkazin, and A. A. Glebov. 2005. Burning mechanism of aluminized solid rocket propellants based on energetic binders. Propellants Explosives Pyrotechnics 30(4):281-90.

22. Babuk, V.A., A. A. Vasil'ev, and V.V. Sviridov. 1999. Modeling the structure of rocket fuel. Combust. Explosion Shock Waves 35(2):144-48.

23. Babuk, V.A., I. N. Dolotkazin, and V. V. Sviridov. 2003. Simulation of agglomerate dispersion at combustion of aluminized solid propellants. Combust. Explosion Shock Waves 39(2):195-203. 